\title{
La diferancia cultural negra en Colombia. Contrapúblicos afrocolombianos*
}

DOI: https://doi.org/10.18046/recs.i29.3631

\author{
Black Cultural Differance in Colombia. \\ Afrocolombian Counterpublics
}

\author{
Carlos A. Valderrama ${ }^{* *}$ \\ Universidad Icesi (Cali, Colombia)
}

\begin{abstract}
* El presente artículo forma parte de una sección de la tesis llamada "The Negritud Movements in Colombia", defendida en el 2017 para optar por el título de Ph. D. en Sociología por la Universidad de Massachusetts, Amherst (Estados Unidos). Artículo de investigación recibido el 03.05.19 y aceptado el 18.07.19.

** Trabajador social de la Universidad del Valle (Colombia). Magíster y Ph. D. en Sociología por la Universidad de Massachusetts, Amherst (Estados Unidos), con una especialización en Estudios Afrodiaspóricos y Latinos de la misma universidad. Investigador asociado al Centro de Estudios Afrodiaspóricos (CEAF) de la Universidad Icesi (Colombia). Correo electrónico: pibeson@gmail.com ORCID: https://orcid.org/oooo-ooo1-8838-8350
\end{abstract}




\section{Cómo citar/How to cite}

Valderrama, Carlos A (2019). La diferancia cultural negra en Colombia. Contrapúblicos afrocolombianos. Revista CS, 29, 209-242. https://doi.org/10.18046/recs.i29.3631 
En el presente trabajo se hace un mapeo de la política cultural negra con el objetivo de señalar cómo se manifestó la diferancia cultural negra en Colombia. Primero, se descentraliza la noción de movimientos sociales para el estudio de los procesos de movilización social y política afrocolombiana. Segundo, se propone el concepto de contrapúblicos afrocolombianos para explorar la emergencia de esferas públicas afrocolombianas descartadas por estudios sobre movimientos sociales en Colombia. Y, tercero, se argumenta que estas esferas públicas de la política negra dieron lugar a la conformación de una estructura política subalterna que permitió la circulación y discusión de temas relacionados con raza, racismo y cultura negra; temáticas y discursos que no encontraron lugar en esferas públicas oficiales (por ejemplo el Estado, los partidos políticos, el Congreso de Colombia, el sistema educativo, las ciencias sociales, etc.) ni sociales (organizaciones de izquierda, sociales y populares).

\section{PALABRAS CLAVE:}

política cultural negra, contrapúblicos afrocolombianos, movimientos sociales, diferancia cultural negra

In this article, we outline the black cultural politics with the aim of pointing out how the black cultural difference manifested itself in Colombia. Firstly, we decentralize the concept of social movements for the study of black politics. Secondly, we propose the concept of afrocolombian counterpublics to explore the emergence of black public-spheres discarded by national and international scholars on social movements. And thirdly, we argue that these black public-spheres gave rise to a subaltern structure of politics through which blacks discussed and circulated issues related to race, racism, and black culture; discussions that were not part of official public-spheres (e.g. State, Congress, social sciences, education system, political parties, etc.) and social organizations (Union, leftist, and social organizations).

\section{KEYWORDS:}

Black Cultural Politics, Afrocolombian Counterpublics, Social Movements, Black Cultural Differance 



\section{Introducción}

La historia de las luchas sociales y políticas afrocolombianas es rica en complejidades y contradicciones; aspectos que, se puede decir, desbordan las fronteras empíricas y conceptuales definidas por teorías sobre movimientos sociales. Hay formas, lugares y apuestas que revelan variadas agendas, proyectos e intereses políticos, sociales y culturales que describen lo que Stuart Hall (1998) llamó la diferancia cultural. El significado de la palabra diferancia describe un movimiento hacia nuevos sentidos de lo diferente sin perder o borrar las huellas de aquello que previamente lo definía como diferente. Es decir, la diferancia supone la construcción de la diferencia en una constante y permanente redefinición de ser diferente dentro de los marcos que han definido lo diferente. En otras palabras, la diferancia se refiere a múltiples formas de ser diferente dentro de aquello constituido como diferente. Así, la diferancia describe los múltiples lugares de enunciación que se encuentran en aquellos grupos humanos definidos como diferentes (Hall, 1998)².

En el presente trabajo, se cartografían algunas de las luchas sociales y políticas afrocolombianas (ver Lao-Montes, 2010), para señalar cómo, en su larga trayectoria, se manifestó la diferancia cultural y política negra en Colombia. Para tal objetivo, se sugiere el concepto de contrapúblicos afrocolombianos. Se sostiene que este concepto permite identificar esferas públicas afrocolombianas que se hallan por fuera de los fenómenos sociales analizados por teorías sobre movimientos sociales; espacios subalternos en los que ideas de raza, racismo e identidad cultural negra se debatieron, cuestionaron y circularon. Estas esferas no solo revelan complejas maneras en las que se manifestó la diferancia cultural negra, sino que también posibilitó la constitución de una estructura política alternativa (ver Eley, 1992) para las comunidades negras.

Por lo anterior, con este estudio se buscó responder a la siguiente pregunta: ¿cuáles fueron las esferas públicas afrocolombianas que permitieron la circulación, discusión y articulación de discursos sobre la identidad cultural y los problemas raciales previos a la década del ochenta? La estrategia metodológica para responder al anterior interrogante fue identificar esferas públicas afrocolombianas que emergieron anterior a la década del ochenta, usando fuentes primarias tales como

1. Según este autor, para escribir la palabra diferencia (en inglés difference), Derrida puso la letra "a" en vez de la letra "e" (diferance vs. difference), para señalar la movilización simbólica de diferentes construcciones de significados de la diferencia como nunca acabada o terminada. La diferancia describe los múltiples sentidos y significados de la diferencia cultural, política y social marcado por las relaciones de poder establecidos por la raza, la clase, el género y la sexualidad

2. La diferancia describe los múltiples sentidos y significados de la diferencia cultural, política y social, marcados por las relaciones de poder establecidos por la raza, la clase, el género y la sexualidad (Hall, 1998: 229). 
entrevistas, prensa nacional, libros escritos por los protagonistas, fotos e informes de reuniones. A lo anterior fue posible darle sentido contextual con la información secundaria disponible (Agudelo, 2005; Hurtado, 2001; Mina, 1975; Pisano, 2012; Roux, 1991; Sanders, 2004). Por los límites propios de un escrito como este, se hace imposible describir y analizar cada una de las esferas públicas que emergieron durante el periodo señalado. Por tal motivo, se hará énfasis en aquellas esferas públicas afrocolombianas que mostraron un carácter nacional (presencia de personas negras de diferentes regiones del país) y que, como tal, permitieron la discusión de agendas locales que se pueden considerar antirracistas. Para el desarrollo de los argumentos expuestos, primero se discutirá la pertinencia del concepto de contrapúblicos subalternos, para proponer una definición de contrapúblicos afrocolombianos. Segundo, se proveerá información empírica sobre la emergencia de esferas públicas afrocolombianas que dieron lugar a la manifestación de la diferancia cultural y política negra. Y, tercero, se reflexionará sobre las implicaciones del uso del concepto contrapúblicos afrocolombianos para el estudio de la política cultural negra en Colombia.

\section{Descentrando las perspectivas de los movimientos sociales}

El estudio de la política negra ha estado dominado por la centralidad dada a las perspectivas y teorías de los movimientos sociales; ; ya sea la perspectiva del proceso político (McAdam, 1999), la identidad colectiva (Melucci, 1996), la política cultural (Álvarez; Dagnino; Escobar, 1998) o el campo político (Fligstein; McAdam, 2012). Estas teorías han permitido plantear la discusión sobre la existencia de un movimiento social afrocolombiano. Sin embargo, se sostiene que han negado o ignorado la existencia de otras formas de lucha política y social que explican la complejidad de la política cultural negra en Colombia. Se parte de la confluencia de organizaciones sociales de nivel nacional, de carácter masivo, cuyos repertorios de acción colectiva son combativos; y de una identidad homogénea. A partir de lo anterior, se ha establecido la emergencia del movimiento social afrocolombiano después de los años ochenta con la conformación de la organización Cimarrón. Así, iniciativas lideradas por Manuel Zapata Olivella y por Amir Smith Córdoba han sido consideradas como esfuerzos individuales, locales, dispersos y desarticulados (ver Wade,

3. La política negra se entiende como un campo diverso de prácticas (acciones y discursos) políticas y sociales a través de las cuales los sujetos afrocolombianos negocian y disputan relaciones de poder (Gregory, 1998). Así, la política cultural negra se refiere al uso de la cultura negra en los procesos de negociación y disputa de las relaciones de poder. 
1995; Hurtado, 2001; Agudelo, 2005; Castillo, 2007; Wabgou; Arocha-Rodríguez; Salgado-Cassiani; Carabalí-Ospina, 2012; Paschel, 2016).

Se considera que lo que se ha mostrado como actos individuales, locales, dispersos y desarticulados fueron en realidad espacios de articulación nacional donde activistas afrocolombianos discutieron, cuestionaron y replantearon construcciones regionales de la identidad negra y sus agendas políticas. De ahí que se proponga una lectura emergente (ver Flórez, 2010) que nos permita acercarnos a esas realidades. Precisamente, una forma de hacerlo puede ser analizando las estrategias que actores sociales y políticos construyen en esferas públicas y cómo estas permiten la circulación y discusión de discursos sobre la identidad negra y los problemas raciales. Se parte de la idea de que si para teóricos como Alberto Melucci los movimientos sociales se constituyen como profetas del mañana, por los mensajes que tienen para la sociedad -mensajes que señalan aquello que los partidos políticos, el Estado y sectores de la sociedad civil se niegan a reconocer (Melucci, 1996) ${ }^{4-}$, más que la espectacularidad de los repertorios de acción colectiva y las formas de organización social nacional, deberíamos de prestar mayor atención a los mensajes y discursos que actores sociales hacen públicos con sus repertorios de movilización. De esta forma, al observar las esferas públicas, podemos estudiar la política negra desde su dimensión discursiva y su impacto en lo público. En este orden de ideas, se propone usar el concepto de contrapúblicos subalternos, planteado por Nancy Fraser (1990) de su crítica a las esferas públicas burgueses originalmente desarrolladas por Habermas (1999).

Para Nancy Fraser (1990), los contrapúblicos subalternos "son arenas discursivas paralelas donde los miembros de los grupos subordinados inventan y circulan contra-discursos, que a su vez les permite formular interpretaciones de oposición sobre sus identidades, intereses y necesidades" (67). El valor analítico que ofrece utilizar el concepto de contrapúblicos se refiere a las posibilidades de observar cómo en estos escenarios se crean nuevas categorías que revelan la dominación. Por ejemplo, "las feministas han inventado nuevos términos para describir la realidad social. Incluye, sexismo, la doble jornada laboral, acoso sexual, violación marital, cita y de conocidos" (67).

Los estudios reportan diversas esferas públicas. Se encuentran las esferas públicas burguesas (Habermas, 1999), feministas (Fraser, 1990; Thayer, 2010), obreras (Eley, 1992) y de la comunidad LGBTI (Warner, 2010). A diferencia de estas, las esferas públicas subalternas del presente estudio hacen alusión a aquellas constituidas por seres humanos racializados y cuyas discusiones, intereses, necesidades y agendas 
se relacionan con ideas de raza, racismo e identidad racial (ver Dawson, 2001; Hanchard, 2006; Singh, 2005). Por ejemplo, para los afroamericanos, fueron lugares en los que se discutió, construyó y circularon conceptos como autodeterminación, autodefensa, colonialismo interno, racismo estructural, el nuevo negro, black is beautiful, el poder negro, entre otros. Nociones, conceptos y construcciones de sentido claves para explicar la subordinación racial y que, posteriormente, se movilizaron en el heterogéneo movimiento social afroamericano: movimiento de los derechos civiles, las Panteras Negras, la Nación del Islam, etc.

Se propone, entonces, el concepto de contrapúblicos subalternos para identificar aquellas esferas públicas afrocolombianas que emergieron anterior a la década del ochenta y que no han sido analizadas con rigurosidad por estudios de los movimientos sociales en Colombia; esferas públicas afrocolombianas que consolidaron una estructura política subalterna en la que, contrario a las esferas públicas oficiales del Estado, por ejemplo, los partidos políticos, el Congreso de Colombia, el sistema educativo, las ciencias sociales, etc., y de otras esferas públicas subalternas, por ejemplo, las organizaciones de izquierda, sociales y populares, abrieron espacios de discusión para la circulación, cuestionamiento y reformulación de asuntos relacionados con la raza, el racismo, la cultura y la identidad negra en Colombia.

Por contrapúblicos afrocolombianos se entiende que son aquellas esferas públicas alternativas donde afrocolombianos, políticos, activistas, folcloristas, literatos, bailarines, intelectuales y músicos construyeron contradiscursos que cuestionaron el orden racial en Colombia y afirmaron revaloraron una identidad racial negra. Estas esferas han sido compuestas por individuos, grupos y colectividades articulados, en muchos casos, en redes de relaciones y colaboraciones. Han sido lugares y formas de la política negra con un carácter flexible; espacios estructurados sobre la base de relaciones sociales; presentan estructuras amorfas dada su flexibilidad de articular diferentes esferas públicas de tipo culturales, sociales y políticas; y son un campo de disputa discursiva debido a la presencia de diferentes agendas políticas, sujetos y sujetas afrocolombianas con diferentes posicionalidades y subjetividades. Lo que sigue, a continuación, es una periodización tentativa de la emergencia, intentos fallidos y consolidación de los contrapúblicos afrocolombianos 5 . 


\section{La emergencia de los contrapúblicos afrocolombianos}

La emergencia de esferas públicas afrocolombianas con un carácter nacional se puede rastrear desde los años cuarenta con la celebración del Día del Negro y la consecuente creación del Club Negro de Colombia y del Centro de Estudios Afrocolombianos. Cada una de estas esferas fue creada en Bogotá por afrocolombianos provenientes de diversos lugares del país. Según se puede interpretar del estudio hecho por Pisano (2012), cada una de estas esferas no solo permitió diálogos sobre identidad negra en la Colombia de los años cuarenta, sino también el desarrollo de una conciencia negra, no ausente de contradicciones y ambigüedades.

En su famoso libro iLevántate Mulato! Por mi raza hablará el espíritu, Manuel Zapata Olivella (1990) relata la manera como se dieron estas discusiones hacia una conciencia negra diferenciada de acuerdo con las dinámicas raciales de las regiones de origen:

Los estudiantes costeños del Caribe nos vimos abocados a violentas confrontaciones, evidentes entre nuestra condición de mulatos o zambos y la etnia puramente negra de los condiscípulos caucanos. En esos encuentros capitalinos en pensiones, aulas y calles discutíamos, sin saberlo, lo más importante de la formación humanística: nuestra propia identidad. “Tú eres negro", "Yo soy mulato”. “Todos somos discriminados” (...). Paulatinamente, dolorosamente, al lado de mi hermana (Delia Zapata) principiamos a desatar el nudo de los complejos raciales inconsciente. (184)

Es claro que no se puede entender el Día del Negro, el Club Negro de Colombia y el Centro de Estudios Afrocolombianos sin reconocer esferas públicas menos formales como fueron las "pensiones", las "aulas" y las “calles" señaladas por Manuel Zapata Olivella. Según se puede inferir, entre otros, participaron Diego Luis Córdoba, Natanael Díaz, Manuel y Delia Zapata Olivella, Helcías Martán Góngora, Marino Viveros, Arquímedes Viveros, Adolfo Mina Balanta; políticos, intelectuales, literatos y folcloristas negros que migraron a Bogotá para cursar estudios profesionales, pero que, al mismo tiempo, vivenciaron el racismo allá. Así, no cabe duda de que estas discusiones sostenidas en los encuentros capitalinos derivaban de las experiencias individuales sobre el racismo a la colombiana. Según Santiago Arboleda (2016), esto hizo que sus participantes miraran "hacia los sucesos de los Estados Unidos y África" (131) para ilustrar sus propias condiciones de discriminación racial en Colombia.

La realización de las manifestaciones públicas descriptas por Pisano (2012) y Zapata Olivella (1990) posibilitó algo más que la discusión y redefinición de identidades negras regionales. En ellas también hay una articulación de diferentes repertorios de acción de la política cultural negra. Por un lado, la marcha. En la celebración del 
Día del Negro en Bogotá ${ }^{6}$, empuñando sus manos en el aire, los protestantes arengaban: “iVivan los negros!”, “¡Abajo la discriminación racial!”, “¡Protestamos por los linchamientos de nuestros hermanos de raza en los Estados Unidos!" y "iViva el África del año dos mil!" (Zapata Olivella, 1990: 189). Por otro lado, acciones culturales y literarias. Los marchantes se tomaron la biblioteca de la Universidad Nacional para exigir "que en toda la mañana se tocara música de nuestros hermanos de raza (afroamericanos)" (Zapata Olivella, 1990:188). Luego se movilizaron hacia uno de los reconocidos cafés de la capital para arengar: “¡Ay mamá Inés! ¡Ay mamá Inés! ¡Todos los negros tomamos café!" (Zapata Olivella, 1990: 189); recitar poemas de Candelario Obeso y Jorge Artel; leer partes de la novela Sangre Negra (en inglés, Native Son), escrita por Richard Wright; bailar cumbia y rumba (Pisano, 2012; Zapata Olivella, 1990).

La emergencia de estas esferas públicas afrocolombianas empezó también a definir la diferancia cultural y la política negra entre sus participantes. Mientras los participantes de la marcha crearon el Club Negro, con la intención de posicionar una identidad racial, Manuel Zapata Olivella, con algunos de los participantes de la marcha, creó el Centro de Estudios Afrocolombiano, para reconocer aspectos culturales e históricos de la identidad del negro (ver Pisano, 2012)7. Es interesante observar que para este momento histórico la formación profesional definió propósitos que no solo consideraban la educación para la participación política y el ascenso social (Agudelo, 2005; Arboleda, 2016; Caicedo, 2013; Pisano, 2012). Con la agenda académica del Centro de Estudios Afrocolombianos y con la aparición de antropólogos afrocolombianos como Rogelio Velásquez y Aquiles Escalante, emergió un nuevo

6. En la marcha participaron al menos 12 estudiantes negros universitarios entre los cuales se encontraban Natanael Díaz, Adolfo Mina Balanta y Marino Viveros, originarios del norte del Cauca; Delia y Manuel Zapata Olivella de Lorica, el Caribe colombiano; y estudiantes del Pacífico norte, Chocó (Zapata Olivella, 1990). Las actividades desarrolladas durante la marcha incluyeron "La presencia de tres a cuatro negros gritando vivas a su raza [que] dentro de las aulas dejaba perplejos a los alumnos. Hasta ese momento, y seguramente después, los mestizos, mulatos, y zambos, y aun los propios negros o indios, jamás se habían cuestionado su identidad étnica. Nos miraban sorprendidos, reivindicadores de una causa inexistente. La mayoría se mostraron molestos porque se les evidenciaría los nexos de sangre que poseían con la raza discriminada” (Zapata Olivella, 1990:188). Por otro lado, el Día del Negro no fue la primera manifestación pública hecha por la población afrocolombiana. Sanders (2004) describe el repertorio de acción política desplegada por afrocolombianos para movilizar sus agendas raciales dentro del liberalismo popular republicano entre 1840 y 1900 .

7. Pisano sostiene que el Centro quiso hacer lo mismo que la antropología hizo con el indio (Pisano, 2012). Se creería que desde una perspectiva nacionalista es cierto lo que dice. Sin embargo, desde una perspectiva afrodiaspórica, la agenda del Centro concuerda con el llamado hacia la creación de centros de estudios afroamericanistas. De ahí la presencia de Fernando Ortiz de Cuba y Arturo Ramos de Brasil como miembros honorarios, y del deseo de intercambios académicos entre los centros de estudio afroamericanistas en Cuba, Brasil y México (Karabalí, 1947:9). 
propósito para la educación con la aparición de disciplinas como la etnología-antropología y los estudios folclóricos. La formación en ciencias sociales y el compromiso con las comunidades negras requirió definir herramientas para el estudio de una cultura negra heredera del África (Valderrama, 2013). La educación así concebida se convirtió en un instrumento que visibilizaba lo que la nación, el mestizaje y el indigenismo pretendieron ocultar: la existencia de una cultural negra en Colombia.

El Club Negro de Colombia y el Centro de Estudios Afrocolombianos fueron intentos organizativos de constituir esferas pública afrocolombianas autónomas y alternativas en Colombia. Ambas esferas tuvieron una corta duración (Pisano, 2012), así como también le ocurrió al Comité de Asuntos Afrocolombianos, creado por Natanael Díaz en Bogotá en 1950 (Mosquera, 2002). Sin embargo, su valor histórico se encuentra en la manera como movilizaron la cultura negra para constituir contra discursos que buscaron afirmar una identidad negra/afrocolombiana y denunciar el racismo en Colombia.

\section{Intentos fallidos de esfera pública afrocolombiana y el contexto de violencia política en Colombia}

Todo parece indicar que la conformación de contrapúblicos afrocolombianos sufrió un revés durante el periodo de la violencia en Colombia. De hecho, me atrevería a sugerir que los acontecimientos políticos surgidos con el asesinato del líder político liberal Jorge Eliecer Gaitán, en 1949, y la criminalización de la protesta social y política (Archila, 2003; Múnera, 1998) impactaron negativamente las condiciones sociales y políticas para el surgimiento de nuevas iniciativas de esferas públicas afrocolombianas de carácter nacional. Así, Manuel Zapata Olivella (1990), Jorge Artel (Prescott, 200o), Marino Viveros (Ayala-Diago, 1988) y Natanael Díaz (Eduardo Díaz Saldaña, comunicación personal, 2016; Mina, 1975) fueron perseguidos y, en otros casos, exiliados por su filiación política a grupos de izquierda (Partido Comunista Colombiano). Por otro lado, la política clientelista y paternalista desarrollada durante del Frente Nacional cooptó la emergencia de una dirigencia política afrocolombiana con conciencia negra/afrocolombiana. En el norte del Cauca, "la dirigencia departamental del liberalismo cooptó dirigentes negros con ascendencia entre sus corraciales, que le sirvieran de punta de lanza para penetrar y conquistar un electorado reacio a ser manejado desde Popayán (Roux, 1991) ${ }^{8}$. En el Chocó, Acción Democrática, liderada por Diego Luis Córdoba, perdió fuerza durante el Frente 
Nacional; además, el liderazgo destacado de Adán Arriaga y Diego Luis Córdoba se plegó al oficialismo liberal que firmó el acuerdo que dio vida al Frente Nacional; esto sumado a la muerte de algunos de los líderes afrocolombianos más destacados de los años cuarenta, por ejemplo, Natanael Díaz, Alejandro Peña y, posteriormente, Diego Luis Córdoba.

Por lo anterior, la dirigencia política afrocolombiana perdió poder de convocatoria popular negra. El escenario público, político y social estaba dominado por dos fuerzas poderosas que difícilmente permitieron alternativas. Por un lado, las fuerzas del oficialismo nacional que movilizaron discursos anticomunistas, apoyados por la intervención estadounidense (por ejemplo, la Alianza para el Progreso) y, por otro, el surgimiento y radicalización de organizaciones de izquierda y guerrilleras (MOIR, M 19, FARC, EPL, ELN, ANUC, etc.) que trajeron consigo discursos de izquierda radicales como el marxismo, trotskismo, leninismo, guevarismo y castrismo, entre otros (Archila, 2003; Múnera, 1998). Así, nuevas fuerzas sociales y políticas oficialistas y de izquierda entraron en las zonas de mayoría negra (Mina, 1975; Roux, 1991). Líderes sociales y estudiantiles afrocolombianos encontraron en estas esferas oportunidades para movilizar sus propias agendas dentro de discursos oficiales y de clase. Estos jóvenes fueron determinantes en la construcción de nuevas esferas públicas afrocolombianas en la década del setenta, ya fuera movilizando o cuestionando el nuevo marco discursivo que se creó con la negritud.

Se podría decir, entonces, que la conformación de contrapúblicos afrocolombianos encontró obstáculos estructurales durante el Frente Nacional que no permitieron su desarrollo. El campo de disputa entre fuerzas socialistas-comunistas y anti-socialistas-comunistas no dejó capacidad de maniobra para la emergencia de discursos políticos alternativos. Paradójicamente, la radicalización política abrió espacios de carácter cultural. Y, aunque las artes, la literatura, el folclore y la cultura fueron escenarios de disputa ideológica entre la izquierda y la derecha (Tirado, 2014), la cultura negra encontró maneras de movilizarse en esferas folclóricas y literarias para construir contradiscursos negros/afrocolombianos.

\section{Redes de relaciones y colaboraciones afrocolombianas}

Hay indicios para sostener que, durante el Frente Nacional, entre 1950 y 1970, la circulación de contradiscursos afrocolombianos, de carácter cultural, literarios y folclóricos, se dio a través de redes de relaciones y colaboraciones nacionales y afrodiaspóricas entre folcloristas, músicos, poetas, novelistas, políticos, bailadores y bailadoras, cantantes e intelectuales negros. Para sustentar lo anterior, cabe 
detenerse a analizar tres escenarios en los que se observa la conformación de esta red: una conferencia organizada por Natanael Díaz, la literatura y, posteriormente, el folclore negro/afrocolombiano.

En conversación con Eduardo Díaz Saldaña, hijo del político liberal negro del norte del Cauca, Natanael Díaz, se pudo observar algunas fotos familiares. En particular, una en cuyo respaldo había una nota a mano que, según Eduardo Díaz, fue escrita por el mismo Natanael Díaz. Esta nota dice: "Conferencia sobre [Alexander] Petión y [Simón] Bolívar en la Luis Ángel Arango, Bogotá D.E. Nov. de 1961". La foto muestra tres personas negras y una blanca-mestiza a lo largo de una mesa, organizadas para la presentación de ponencias. Según dicen otras notas, los tres hombres negros serían el afrocolombiano Natanael Díaz y dos activistas e intelectuales haitianos. Uno fue Paul Arcelin y el otro nombre fue difícil identificarlo. La persona mestiza o blanca sería Rubén Darío Hurtado, quien fuera compañero de oficina de Natanael Díaz (Eduardo Díaz Saldaña, comunicación personal, 2016). Esta conferencia invita a considerar la posible y constante relación de los afrocolombianos con la intelectualidad afrodiaspórica como un proyecto de afinidad política y cultural; en este caso con los haitianos. A juzgar por el nombre del evento, la temática de la conferencia pudo haber sido sobre la relación entre Alexander Petión y Simón Bolívar en las guerras de independencia y la promesa no cumplida de liberar a los esclavizados por este último. En todo caso, desarrollar una conferencia que ponga en el escenario nacional una discusión que relacione al libertador Bolívar y a Petión es visibilizar relaciones afrodiaspóricas entre Colombia y Haití que la historia nacional ha querido ocultar.

Desde el punto de vista literario, hubo una voluntad de los intelectuales afrocolombianos por hacer visibles los trabajos que cada uno de ellos estaba realizando individualmente. Tenemos entonces que desde el año de la creación del Centro de Estudios Afrocolombianos por Manuel Zapata Olivella, Natanael Díaz publicó un artículo periodístico llamado "Diego Luis Córdoba: un negro visto por otro negro", en el periódico capitalino Sábado (1947). En este artículo periodístico, Diego Luis afirma que es marxista y negro:

(...) en el Chocó, la clase explotada es la negra y la explotadora la blanca. Hay desde luego excepciones: negros explotadores. Por eso, mis convicciones y mis campañas me han hecho chocar con algunos hermanos de raza. (...) el día que los negros tengan las posiciones económicas, intelectuales y sociales a que tienen derecho, ese día no tendrá razón mi lucha racial. (Díaz, 1947: 2; ver Arboleda, 2016: 226)

En 1959, Helcías Martán Góngora dedicó un poema a Delia Zapata Olivella llamado "Canto negro para Delia Zapata" en El Tiempo (1959). Aquí un pequeño fragmento: 
Dalia de música, dédalo tambores, laberinto Incendiado en el límite de la oscura floresta. Delia Zapata, rama de un árbol de tinieblas. En tu bosque de siglos tejes, sobre la arena, la danza de los ríos que copulan la tierra (...). (2)

En 1961, Lleras Restrepo publicó tres artículos de entrevistas hechas a Diego Luis Córdoba ("Un líder de Color") y a Rogelio Velázquez ("La vida de los estudiosos" y "La magia de la Cumbia"). En el primer artículo, Diego Luis Córdoba reconoce una lista larga de figuras negras/afrocolombianas que contribuían al movimiento afrocolombiano9. En el segundo artículo, "Velásquez le reprocha su tendencia a dejar caer la tea de la lucha (...) de la afirmación racial" a los compañeros del Cauca. Por otro lado, en 1949, Arnoldo Palacios conoció a Manuel Zapata Olivella en Bogotá (ver Foto 1). Parece ser que eran muy cercanos. Cuenta Oscar Collazos cuenta que Manuel Zapata fue quien incentivó a Arnoldo Palacios a reescribir la novela Las estrellas son negras, destruida durante el Bogotazo. Luego, Manuel Zapata Olivella medió para que Clemente Airó publicara la novela (Collazos, 2010). Días después, Rogelio Velásquez (1949) publicó un artículo llamado “Las estrellas son negras”, en el cual valoró la novela de Arnoldo Palacios. Años más tarde, en 1953, Manuel Zapata Olivella apoyó a Rogelio Velásquez con la publicación de su novela, Las memorias del odio (Prescott, 200o). Según Cristina Isabel Velásquez, hija del intelectual y antropólogo Rogelio Velásquez, Manuel Zapata Olivella lo visitaba con mucha frecuencia en Quibdó. Hablaban mucho de folclore y etnografía (Cristina Isabel Velásquez, comunicación personal, 2015).

El folclore fue el escenario más rico en posibilidades para que los contradiscursos afrocolombianos pudieran circular; también, uno de los más ambiguos. Hubo varias agendas folclóricas durante este periodo ${ }^{10}$. Sin embargo, compartían el interés de visibilizar la cultura negra de sus regiones, ya fuera a través de presentaciones artísticas de danzas y músicas folclóricas (Birenbaum, 2009) o de escritos académicos

9. Entre los médicos menciona a los hermanos Juan y Manuel Zapata Olivella. En derecho menciona a Adán Arraiga Andrade y Daniel Valois Arce. Entre los artistas y literarios menciona a la folclorista Delia Zapata Olivella y Francia Oliva Vega. De los poetas a Jorge Artel, Hugo Salazar Valdés, Natanael Díaz y Arnoldo Palacios. En la literatura también destaca las novelas de Manuel Zapata Olivella y Teresa Martínez. Finalmente, en la política reconoce el papel fundamental de Manuel Saturio Valencia, Luis A. Robles y Sofonías Yacub.

10. Estaban quienes lideraron agrupaciones folclóricas de danza y teatro como los hermanos Delia y Manuel Zapata Olivella del Caribe colombiano. En Buenaventura, Teófilo Potes, Mercedes Montaño y Alicia Camacho. En Chocó, se destacaron la folclorista Madolia de Diego y Antero Agualimpia. En el norte del Cuaca, los Macheteros del Cauca. En la música se destacaron, entre otros, del norte del Cauca, Leonor Gonzales Mina. De Guapi, Esteban Cabezas. En Buenaventura, Peregoyo y su Combo Vacana. En Chocó se destacó Alfonso Córdoba. Finalmente, en los estudios folclóricos, además de los Hermanos Zapata Olivella, se destacaron el chocoano Rogelio Velásquez y Aquiles Escalante del Caribe colombiano. 


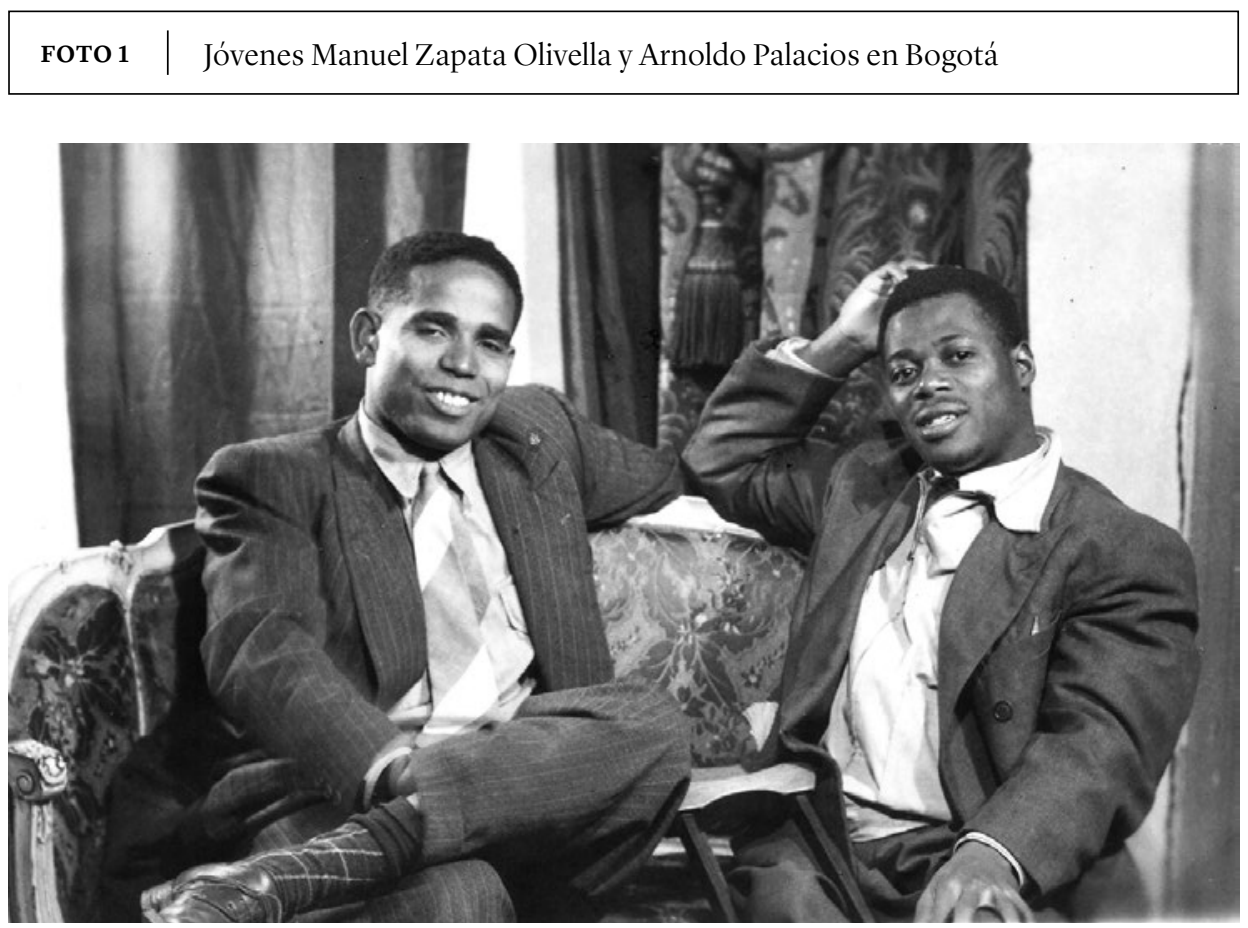

Fuente: archivo personal de Arnoldo Palacios. Cedida a través de Aurora Vergara por José Venancio (2018).

sobre las tradiciones culturales negras (Valderrama, 2013). Según se pudo rastrear, la red de relaciones y colaboraciones incluyó apoyos personales entre intelectuales, folcloristas y músicos; red que tuvo como nodo central a los hermanos Delia y Zapata Olivella. En un primer momento, la red de colaboración implicó apoyos para el estudio, recopilación y montaje de prácticas tradicionales afrocolombianas en danzas coreográficas. En Buenaventura contaron con el apoyo de folcloristas como Teófilo Potes y Mercedes Montaño. En Chocó, con Teresa Martínez de Varela, Antero Agualimpia, Rogelio Velásquez y Madolia de Diego, quien participaría de las agrupaciones folclóricas de Delia Zapata Olivella. En el norte del Cauca, con Leonor y Raúl Gonzales Mina, Alonso Sandoval de los Macheteros del Cauca. En el Caribe colombiano tuvo relaciones cercanas con Aquiles Escalante, Jorge Artel, Orlando Fals Borda, etc.

Las colonias chocoanas, guapireñas, bonaverenses y demás que surgieron durante este periodo van a ser fundamentales en la reproducción de prácticas culturales y tradicionales afrocolombianas en centros urbanos andinos (Arboleda, 2016). 
La conformación de una red de relaciones y colaboraciones en el ámbito del folclore fue mucho más amplia de lo que se pudiera analizar en este trabajo. Sin embargo, lo presentado hasta aquí permite sostener que poetas, intelectuales, folcloristas y músicos afrocolombianos cultivaron una relación de apoyo, admiración y reconocimiento mutuo. Es decir, no fueron proyectos culturales del todo aislados uno del otro. No se tiene información para sostener que fueron proyectos construidos colectivamente. Sin embargo, hubo una política negra cultural que los unió en clave de lo que Santiago Arboleda (2016) llama suficiencias íntimas: "orientaciones mentales, claves epistémicas y prácticas sociales, no necesariamente reactivas, que despliega un grupo concretando y afirmando su existencia” (27). Así, compartieron el deseo de visibilizar una cultura negra y sus tradiciones, ya fuera a través de danzas coreografías, composiciones musicales, obras de teatro; libros de novela, poesía y ensayos literarios, o investigaciones científicas ${ }^{11}$.

\section{Consolidación: esferas públicas de la negritud}

La consolidación de contrapúblicos afrocolombianos se desarrolló dentro del movimiento literario y cultural de la negritud. Mientras sus fundadores y promotores despidieron la negritud como marco de referencia identitario afrodiaspórico por su incapacidad de articular diferencias de clase y reconocer la explotación económica sobre el hombre (Depestre, 1984), en Colombia, y en Latinoamérica (Brasil, Colombia, Perú, Panamá, Ecuador, Venezuela, etc.), se inició el movimiento de la negritud. Ya entrados los años setenta, la red de relaciones y colaboraciones liderada por Manuel Zapata Olivella incluyó la configuración de esferas públicas afrocolombianas tales como las tertulias y los círculos académicos afrocolombianos. En los rastreos realizados en el marco de este trabajo, se pudo establecer que Manuel Zapata Olivella se reunió con Soweto en Pereira (Eusebio Camacho, comunicación personal, 2015) y con una colectividad de estudiantes afrocolombianos de la Universidad del Cauca, en Popayán, liderada por Eliecer Hurtado; Aura Rosmira; Stella Vida, cuñada de Leonor Gonzales Mina, y el hijo de Juan Zapata Olivella, Alexis Zapata Olivella (Aura Rosmira y Stella Vida, comunicación personal, 2015), para hablar del tema de la negritud o la trietnicidad. En Cali, cuenta la lideresa Rosalba Castillo que Manuel Zapata Olivella "hizo la presentación y habló de las trietnias; empezó a decir que

11. Es necesario analizar cómo el folclore nacional empezó a ser usado en las campañas políticas electorales de grupos de izquierda, liberales y conservadores (el folclore de la política); y su "espectacularización” en los emergentes mercados culturales del momento. Se creería que estos dos escenarios "folclorizaron" no solo las prácticas tradicionales y populares, sino también los estudios folclóricos. Será tema de próximas reflexiones. 
éramos una mezcla de los negros, los mestizos, los indios; que él era la demostración [un] mulato, (...) pero que había mucha discriminación" (Rosalba Castillo, comunicación personal, 2015). En Bogotá, Manuel Zapata Olivella participó en espacios de tertulia organizados por la Agrupación Joven Internacional José Prudencio Padilla, conformada por estudiantes afrocolombianos de las universidades Libre y Nacional que provenían de Buenaventura, Chocó y el Caribe colombiano.

Esferas públicas afrocolombianas que proyectaron la consolidación de contrapúblicos afrocolombianos. En ellas se encubaron los proyectos culturales y políticos que, posteriormente, darían paso a organizaciones y colectividades de importancia nacional en los setenta. En cada una de estas esferas públicas afrocolombianas, la cultura negra, la organización y las acciones políticas se expresaron de manera diversa. Entre algunas de ellas es importante destacar las siguientes: el proyecto de la "negritud mestiza", liderado por los hermanos Juan, Delia y Manuel Zapata Olivella en Bogotá y el Caribe, el cual reclamó la mezcla racial y cultural entre afrocolombianos, indígenas y blancos para posicionar la identidad negra y sus aportes a la nación; el proyecto de "la negritud liberal", liderado por el chocoano Valentín Moreno en Cali, el cual entendía que el problema del racismo se resolvería ocupando puestos públicos para viabilizar y movilizar las agendas y necesidades afrocolombianas; y el proyecto que se llamó "desavasallamiento cultural" ${ }_{12}$, liderado por el chocoano Amir Smith Córdoba en Bogotá, y el cual buscó la descolonización mental de las personas negras ${ }^{13}$.

Proyectos culturales y políticos que, entre otros, ejemplificaron la constitución de la diferancia cultural negra al reclamar tres maneras de ser negro/afrocolombiano dentro del marco discursivo de la negritud. Para el ejercicio de la presente reflexión, se hará énfasis en aquellos espacios de discusión liderados por los proyectos negritud mestiza, negritud liberal y el desavasallamiento cultural, que permitieron la emergencia de esferas públicas afrocolombianas de un carácter nacional. Estos fueron el Primer Congreso de la Cultura Negra de las Américas, organizado por Manuel Zapata Olivella; los encuentros locales, regionales y nacionales de la negritud organizados por Valentín Moreno; y los seminarios culturales para la formación de profesores liderados por Amir Smith Córdoba.

12. Amir Smith Córdoba habló de avasallamiento cultural para describir el proceso de colonización mental del negro. Lo que él llamó la despersonalización del negro, que sería algo así como "la colonialidad del ser", propuesta por Nelson Maldonado Torres. Entonces, el desavasallamiento cultural implica las acciones políticas que buscan revertir tal colonización. El desavasallamiento cultural es una práctica cultural y política que busca la descolonización del ser. Ver Valderrama (2018a: 258-292).

13. Estas agendas políticas y otras se encuentran bien analizadas y desarrolladas en Valderrama (2018a). Lo que se presenta a continuación es un resumen de ellas. 


\section{Primer congreso de la cultura negra de las Américas}

Los Congresos de la Cultura Negra de las Américas se realizaron en Cali (1977), Panamá (1980) y Brasil (1982). En ellos se congregaron intelectuales, activistas, folcloristas e investigadores sociales de diferentes lugares de la diáspora africana para discutir aspectos relacionados con raza, racismo, cultura, África, identidad y negritud; por lo que sus dinámicas constituyeron esferas públicas afrodiaspóricas. Por otro lado, los congresos de la cultura negra en las Américas significaron la consolidación de una red de relaciones y colaboraciones trasnacionales que Manuel Zapata Olivella venía construyendo desde el Día del Negro. Por limitaciones de tiempo y espacio, analicemos algunos aspectos centrales que nos permitan describir aspectos sobre raza, racismo, cultura e identidad negra que el primer congreso desarrolló bajo el marco discursivo de la negritud.

Este encuentro afrodiaspórico se realizó entre los días 24 y 28 de agosto de 1977. Fue convocado por la Fundación Colombiana de Investigación Folclórica, el Centro de Estudios Afrocolombianos, liderados por Manuel Zapata Olivella, y la Asociación Cultural de la Juventud Negra Peruana. Se presentaron doce ponencias y cuatro conferencias magistrales relacionadas con las cuatro áreas de trabajo definidas así: a. Etnia Negra y Mestizaje; b. Filosofía y Afectividad; c. Creatividad Social y Política; y d. Creatividad Material y Artística. Finalmente, se definieron tiempos para el debate por áreas de trabajo y plenaria. Los delegados provenían de diferentes partes de Colombia, África, el Caribe y Norteamérica ${ }^{14}$; lo que de facto contradice aquellas ideas sobre la desarticulación, dispersión e individualización de esfuerzos en la realización de acciones culturales y políticas como el Primer Congreso de la Cultura, si consideramos quiénes fueron los actores afrocolombianos que participaron en él'15.

Los resultados de las comisiones revelan una serie de nociones y conceptos que dan cuenta de la emergencia de contrapúblicos. Fueron creadas nuevas categorías para explicar y describir la situación del negro en las Américas. Por ejemplo, la

14. Angola (1); Brasil (6); Costa Rica (1); Chile (1); Ecuador (4); Egipto (1); España (1); Estados Unidos (23); Honduras (3); México (1); Nigeria (3); Panamá (8); Perú (2); Puerto Rico (1); Senegal (3); y representantes de la Unesco y la OEA.

15. Entre los 63 colombianos que participaron se encuentran los afrocolombianos y afrocolombianas Rosalba Castillo; Carlos Calderón, del Chocó; Jorge Artel y Aquiles Escalante del Caribe Colombiano; Helcías Martán Góngora y Agustín Revelo de Guapi; Marino Viveros Mancilla del norte del Cauca y quien participó del Día del Negro; Delia y Manuel Zapata Olivella; Rosa Bosch, esposa de Manuel Zapata, y su sobrino Alexis Zapata, quien fuera miembro del grupo de trabajo negro en la Universidad de Popayán. Algunos intelectuales blanco-mestizos que participaron fueron Nina S. de Friedemann, Nancy Motta y Jaime Arocha. Estos intelectuales serían claves luego en la reforma constitucional (Agudelo, 2005). 
Comisión de Etnia Negra ${ }^{16}$ y Mestizaje (1988) definió que una identidad étnica es "cuando un individuo es señalado como negro y cuando él se siente negro (...), esta identidad es fundamento de una etnia negra" (145). Discriminación racial es "cuando el individuo o grupo que no es negro y que ejerce el poder para negarle recursos económicos, educativos, políticos o religiosos a un negro o a un grupo de negros, estamos frente a la discriminación racial" (145).

En América Latina se práctica la discriminación racial de manera solapada, sutil, abierta o encubierta. Tal discriminación utiliza las diferentes tonalidades del color epidérmico del negro como mecanismo para lograr que el hombre negro desaparezca a través de la ideología del blanqueamiento (...). (Comisión Etnia Negra y Mestizaje, 1988: 145)

La anterior definición se diferencia de la forma como se entendió el racismo para el caso de los Estados Unidos. El informe dice:

(...) cuando la discriminación racial está regulada por leyes e instituciones de un país, estamos frente al ejercicio del racismo. Aunque en los Estados Unidos ciertas leyes (...) del racismo se abolieron, (...) se ejerce la discriminación racial a nivel privado e institucional de una manera que pretende ser encubierta, y que continúa protegida por la ley. (Comisión Etnia Negra y Mestizaje, 1988: 145)

La comisión estableció que los problemas sufridos por descendientes africanos de las Américas no se resuelven con reformas de naturaleza utópica, "sino que se necesitará un cambio básico estructural de la sociedad y del sistema económico-político vigente" (Comisión Etnia Negra y Mestizaje, 1988: 147). Lo anterior, debido a que el "sistema capitalista difunde la ilusión de igualdad étnica, pero en la práctica ejerce acciones discriminatorias al no dar oportunidades similares a las capas negras e indígenas (...)" (Comisión Creatividad Social y Política, 1988: 156) ${ }^{17}$.

Se quiere destacar la discusión que se suscitó acerca del concepto de negritud. Esta refleja las tensiones y debates generados en el Congreso. El informe registra que:

16. En adelante se señalará en cursiva aquellas palabras y conceptos usados en el Congreso y que en la actualidad han sido considerados de uso exclusivo del movimiento social afrocolombiano. La intención es puntualizar aquellos términos y referencias que fueron usados previos a la Constitución de 1991, la Ley 70 de 1993 y el multiculturalismo estatal para establecer una posible trayectoria de uso de los términos desde entonces.

17. En este punto se quiere señalar cómo el Congreso articula discursos de clase y raza para explicar la situación económica y social de las comunidades negras; aspectos que los diferencian del movimiento de la negritud francófono. 
Se ha señalado que, aunque la Negritud afirma que todos los negros son parte de una familia y pueden tener un sitio en África, no se trata de una vuelta en masa al continente africano, si no de la identificación con la cultura negra y la lucha en los diversos países donde el negro esté presente, para defender esta identificación y esta cultura. (Comisión Etnia Negra y Mestizaje, 1988: 147)

Por otro lado, se señaló "la existencia de una manipulación de los elementos de la cultura negra-africana por parte de las sociedades dominantes blancas como instrumento de dominio y sujeción" (Comisión Etnia Negra y Mestizaje, 1988: 147). Por lo cual fue necesario aprobar la siguiente declaración: “(...) se considera la negritud como una estrategia alternativa de participación y reclamo de derechos en Colombia y en los otros países asistentes al Congreso" (Comisión Etnia Negra y Mestizaje, 1988: 147). Por ello, la Comisión Creatividad Social y Política (1988) expresó que, aun cuando:
(...) exalta el movimiento de la negritud iniciado en 1932 por los intelectuales negros Leopoldo Sedar Senghor, Aime Cesaire y León Damás (...), los negros afroamericanos necesitan crear su propia ideología en las luchas de la liberación cultural [y] en su lucha contra la opresión colonial. (156)

De la Comisión Filosofía y Efectividad (1988) destaquemos lo siguiente: "El trabajo esclavo negro tuvo una importancia decisiva para el enriquecimiento de los blancos europeos y criollos durante la Colonia. Este proceso fue común a los EE. UU. y a América Latina" (151). Con la abolición de la esclavitud, el estatus del negro pasó de ser esclavo a ser definido por su inferioridad social y económica en la vida republicana. Ha habido transformaciones solo en el plano puramente formal, pero en la práctica "la población descendiente del África negra continúa en una situación de dependencia y paternalismo". Así, "la correlación existente entre raza y clase social ha impedido que el negro identifique con claridad las razones de la discriminación social de la cual es víctima" (Comisión Filosofía y Afectividad, 1988: 151).

Es importante señalar el reconocimiento hecho al papel histórico de las mujeres negras en las luchas sociales, culturales y políticas de las comunidades negras y la doble opresión que sobre ellas recae. La comisión manifiesta que se debe reconocer el "importante papel histórico de la esclava negra en su continua lucha por la libertad, como también en asegurar la supervivencia de su raza" (Comisión Filosofía y Afectividad, 1988: 151). Además, se pide a todos: 
(...) los hombres negros de todo el mundo (a) reconocer que el logro de un mundo renovado (...) depende, en gran parte de la liberación de la mujer negra, del peso impuesto por el estereotipo doble, que circunscribe su existencia a las funciones de objeto sexual y reproductor. (Comisión Filosofía y Afectividad, 1988: 151)

Finalmente, se quiere destacar algunos aspectos discutidos sobre la política del folclore negro. La Comisión Creatividad Material y Artística (1988) declaró: "la contribución del negro a la música y la danza no ha sido reconocida en el grado que se merece" (160). Ha habido una apropiación cultural del folclore negro por parte de la sociedad blanca-mestiza, lo cual ha significado que haya "muchos rasgos de la danza característicamente africana [que] han sido incorporados a las formas actuales de danza espectáculo". Por ello, la comisión hizo un llamado a reconocer el "concepto equivocado existente alrededor de la danza [al] asociar al negro con la misma; siendo ello una expresión muy importante no es la única ni la más alta revelación de la misma" (Comisión Material y Artística, 1988: 160). Dado el reconocimiento de un modelo de folclore negro distorsionador, la comisión propuso elementos que hacen de la cultura negra distinguirse de la anterior. De esta manera, una forma de distinguirla de la mirada blanca-mestiza del folclore negro es considerarla una cultura negra libertaria: "el papel creador de los negros en América al utilizar las formas religiosas africanas como un elemento cohesionador de las comunidades negras (...). (Por eso) estimula las formas religiosas afroamericanas siempre que contribuyan a fortalecer la unidad y la lucha de las comunidades negras para su liberación social y espiritual" (Comisión Material y Artística, 1988: 155). Así, la política del folclore negro se transforma. Ya no es solo importante el hecho de demostrar la existencia de una cultura negra a través de la danza, la música y las tradiciones, sino que también debe facilitar la organización social y política negra. Es el único camino para superar la folclorización que ve la cultura negra como un espectáculo.

\section{Encuentros locales, regionales y nacionales de la negritud}

Una de las esferas públicas afrocolombianas que contribuyeron significativamente a la consolidación de un contrapúblico afrocolombiano fueron los encuentros promovidos por el Consejo Nacional de la Población Negra en Colombia desde 1975. Esta organización afrocolombiana se creó en Cali, en su primer encuentro nacional, liderado por el político liberal Valentín Moreno Salazar. Su orientación fue eminentemente liberal. 
El Consejo Nacional se constituyó como organismo representativo del negro colombiano para procurar su integración, culturización y combatir la subestima operante en su contra. También para luchar por una Colombia más igualitaria para todos los colombianos. Hemos considerado que, para lograr nuestros objetivos, tenemos que utilizar los mismos instrumentos que el sistema democrático tiene y que ha venido utilizando el poder político para cristalizar sus privilegios. (Arboleda, 2016:137)

Aunque es una agenda liberal, se trata de un liberalismo negro que, a diferencia del liberalismo político de los partidos tradicionales, reconoce prácticas institucionales de discriminación racial que no permiten la plena integración de la población negra al desarrollo económico del país. Por lo cual, se comparte con Arboleda que en estos planteamientos se encuentran antecedentes de lo que "hoy llamaríamos ciudadanías diferenciadas" (Arboleda, 2016: 137).

La población negra colombiana ha venido siendo subestimada y se le ha venido considerando como un ente sin importancia y sin capacidad que no merece ocupar los peldaños de la vida pública, ni tomar posiciones en la conducción de Estado. Así, por ejemplo, a un negro no se le admite en la escuela de marina, en la de aviación tampoco. No puede hacer carrera militar. Ministerios, embajadas, gobernaciones, gerencias de institutos descentralizados y otros cargos de importancia le son vedados. Estas y otras razones que serían interminables enumerar en estos momentos son la razón del movimiento nacional de negritudes. (Sigue la discriminación racial, 1977)

La estrategia utilizada para movilizar estos planteamientos fue la realización de encuentros nacionales, regionales y locales. A partir de los encuentros, el Consejo Nacional creó comités regionales en el Chocó, Bogotá, Medellín, Tumaco, Buenaventura y Cartagena; y comités de veredas en el sur del Valle y norte del Cauca (Jamundí, Quinamayó, Puerto Tejada, Robles), y centro del Valle (Guacarí). A su vez, formaron comités en los barrios de Cali. Así lo recuerda Adelina Abadía Villegas quien fuera fiscal del Consejo Nacional.

Íbamos a Vivienda Popular, María Mallarino, 7 de agosto, La Floresta, Popular, El Hormiguero, El Popular, y allí se armaron comités y por ejemplo nosotros dejábamos quien organizara, cuando tenían algo nosotros volvíamos. Les decíamos por qué teníamos que organizarnos los negros para participar en decisiones del Estado (...). Queríamos tener un trabajo de bases para hacer política. (Adelina Abadía Villegas, comunicación personal, 2015)

Queda claro que sus objetivos fueron eminentemente políticos y electorales. Lo que motivó a establecer una alianza con Juan Zapata Olivella, intelectual liberal del 
Caribe colombiano perteneciente al proyecto de la negritud mestiza, para lanzar el partido político negro "Movimiento de las Negritudes y el Mestizaje de Colombia", y la candidatura a la Presidencia de la República (Valderrama, 2018a: 345).

La visión liberal y los intereses político-electorales y partidistas generaron una serie de cuestionamientos y debates en los encuentros locales, regionales y nacionales. Esta visión liberal de la negritud fue cuestionada duramente por afrocolombianos de izquierda quienes vieron, inicialmente, la posibilidad de articular procesos de cambio social en los encuentros del Consejo Nacional de la Población Negra de Colombia y sus Encuentros. La aparición de la diferancia cultural y política no se hizo esperar. Mientras líderes políticos como Valentín Moreno Salazar y Bonilla Perlaza concibieron la organización como el resultado de:

(...) un grupo de profesionales [que] acordamos realizar un encuentro de negritudes en la ciudad de Cali, a nivel intelectual, para dilucidar sobre los diferentes tópicos que han venido atajando la superación del negro colombiano y buscar el camino que permitiere destruir esas barreras. (Sigue la discriminación racial, 1977)

Para Luis Enrique Dinas Zape, exmilitante del MOIR y luego fiscal del Consejo Nacional, la organización sería un espacio para discutir asuntos de la negritud que no se discutían en las esferas de izquierda, liberales y conservadoras.

Ser negro no se discutía, [ya] sea [en las esferas] liberal, conservador, comunista, el que fuera; ni veíamos en la negritud la causa de nuestros problemas. Es más, cuando nos estaban quitando a bala las tierras [en el norte del Cauca], los asesinos nos decían negros cachiporros (negro liberal pobre). Creíamos que era por liberales, no por negros, pero a los blancos liberales no los perseguían. (Luis Enrique Dinas Zape, comunicación personal, 2015)

Además, para él la agenda política establecida por Valentín Moreno Salazar era una propuesta con un "discurso flojo, sin contenido [y] ventijuliero de la misma jerga mentirosa" (Luis Enrique Dinas Zape, comunicación personal, 2015). Desde el primer Encuentro Nacional realizado en Cali, entre los días 21 y 23 de febrero de 1975, la disputa y lucha ideológica entre estas dos tendencias políticas se manifestó al interior de la organización y de los encuentros de la negritud. Hernando Rodríguez, exmilitante del MOIR, cuestionó los principios ideológicos del encuentro. Recuerda que:

Cuando llegué, sentí en el ambiente que la gente no estaba contenta y me jalo un discurso moirista. Cuando hablé (...) yo decía que en el movimiento obrero debían caber negros, blancos, indios, en la gran casa del proletariado, (...) y que en ese orden 
de ideas no debían existir distingos, que no nos dejáramos marcar como liberales o conservadores, con una política más bien de tipo socialista y que no nos dejáramos poner la coyunda de los mismos negros. Si renunciamos a la esclavitud, de parte de los blancos, porque teníamos que dejar que los mismos negros nos exploten (...). (Hernando Rodríguez, comunicación personal, 2015)

El estudio de Santiago Arboleda (2016) muestra las tensiones que se presentaron entre estas tendencias políticas. Sostiene, por ejemplo, que mientras los comités creados en el sur del Valle, norte del Cauca y en la Costa Caribe propusieron el:

(...) tema del problema agrario y la pérdida de los territorios que devoraba a pasos agigantados el desarrollo de los ingenios; [y] para el caso del Pacífico también aparece el problema de la (sic) llamadas "tierras baldías", para las cuales se solicita titulación al INCORA. (El tema no se desarrolló) como un elemento central dentro del movimiento (con) epicentro en Cali, desde donde se dinamizaba y se tomaban la mayoría de decisiones. (138)

Tensiones como las anteriores se vivieron durante gran parte de la vida de la organización. Por tal motivo, el Consejo Nacional de la Población Negra de Colombia debe ser entendido como un terreno de disputa y lucha política entre dos tendencias políticas que se disputaron su control y agenda política. Lo anterior produjo una serie de conflictos ideológicos y políticos al interior que se reflejó en “(...) su fragilidad y son frecuentes las acusaciones mutuas de incumplimientos de los miembros, la inmovilidad y el poco funcionamiento de los distintos consejos y comités" (Arboleda, 2016: 138). Así, Luis Enrique Dinas Zape asumió el liderazgo del Consejo Nacional a inicios de la década del ochenta. Esta segunda etapa del Consejo Nacional asumió una agenda política de corte socialista, pero con mucho menor impacto a nivel nacional. Su área de acción se redujo a algunos pueblos del norte del Cauca y barrios de la ciudad de Cali.

\section{El movimiento de la cultura negra}

El movimiento de la cultura negra buscó articular diferentes expresiones de la política negra nacional en Colombia. Sus estrategias o repertorios de acción fueron principalmente de tipo cultural, literario y periodístico. Como esfera pública de la negritud, el movimiento de la cultura negra en Colombia creó lo que podría ser una prensa de la negritud (o Black press) dedicada a la difusión y circulación de las problemáticas relacionadas con la discriminación racial, la cultura e identidad negra, la clase y el colonialismo. El movimiento de la cultura negra publicó tres ediciones 
de la revista Negritud, el periódico Presencia Negra y tres libros de ensayos e investigaciones científicas ${ }^{18}$.

La revista Negritud y el periódico Presencia Negra se convirtieron en un medio o plataforma para la difusión nacional de un pensamiento crítico afrocolombiano que reveló el racismo, afirmó la identidad cultural negra y su legado africano. Para su distribución, el movimiento cultural creó una red de relaciones y colaboradores que permitió la circulación de la revista y el periódico a nivel nacional. Según lo expresado por el intelectual afrocolombiano Dolcey Romero del Caribe colombiano, Amir Smith Córdoba tenía "gente a donde él le mandaba el periódico, lo distribuía y después cuando hacíamos los seminarios pues asistía esa gente" (Dolcey Romero, comunicación personal, 2016). Opinión que compartió Emilia Eneida Valencia de la organización Amafrocol. Ella misma fue una de las personas que, siendo participante de la colonia chocoana, distribuyó el periódico en la ciudad de Cali en la década del ochenta (Emilia Eneida Valencia, comunicación personal, 2015) ${ }^{19}$.

$\mathrm{Si}$ analizamos los intelectuales que publicaron en la revista Negritud, podemos observar que hubo un reconocimiento del trabajo de intelectuales o figuras destacadas negras más allá de los conflictos ideológicos que entre ellos se presentaran. Por citar un ejemplo, Manuel Zapata Olivella publicó un trabajo en la revista Negritud n. ${ }^{\circ}$, a pesar de que su proyecto de la negritud mestiza rivalizó con el proyecto de desavasallamiento cultural que la revista Negritud promulgaba gracias a su director Amir Smith Córdoba.

Por otro lado, hay términos, conceptos y categorías que hacen valiosos aportes en la compresión de la subordinación racial del negro en Colombia. Entre ellos se encuentran avasallamiento cultural, pigmentocracia, endilgación cultural, discriminación racial, raza, racismo, despersonalización negra, la colonización, la supremacía blanca internacional, valores de la superioridad de la cultura occidentaly la civilización occidental blanca. Por otro lado, hay un lenguaje que busca el desavasallamiento cultural del negro, como "Movimiento Cultural Negro", "Negritud”, “Cultura e

18. Estos son Cultura Negray Avasallamiento cultural (1980), Viday obra de Candelario Obeso (1984) y Visión socio-cultural del negro en Colombia (1986).

19. La red de relaciones y colaboraciones también se puede rastrear observando a los intelectuales que formaron parte del comité editorial de la revista y el periódico. Entre ellos aparecen Rogelio Castillo C., José E. Murillo, Ndong Ondo A., Rafael Cortes V., Nina de Friedemann, Valentín Moreno S., Sebastián Salgado, Terry Hayes, Willy Caballero, Marco Realpe B., Manuel de Diego, Venancio Palacios, Ricardo Esquivia y Pablo Rivas; y como colaboradores especiales, Aquiles Escalante, José Consuegra, Miguel Caicedo, Tufik Meluk Aluma, Manuel Zapata Olivella, Carlos Calderón Mosquera y Santiago Pinto Vega. Figuras e intelectuales destacadas que no necesariamente compartían del todo los presupuestos ideológicos de la negritud promovidos por el proyecto de desavasallamiento cultural (Valderrama, 2018a). 
Identidad Negra", "descolonización", “conciencia negra"º. Entre otros términos que se usaron desde los setenta que se pueden encontrar en la revista y el periódico del movimiento, se encuentra el termino grupo étnico: “(...) una unidad de criterio que nos oriente con paso reivindicativo como grupo étnico esclarecido que debe encontrar su puesto en el ámbito operativo que mueve nacionalmente la vida del pueblo colombiano" (Smith-Córdoba, 1977: 25-26) ${ }^{21}$.

El movimiento de la cultura negra en Colombia organizó y lideró cinco seminarios sobre Formación y Capacitación de Personal Docente en Cultura Negra entre 1978 y 1983. Se deben destacar los siguientes aspectos que permiten sostener los argumentos sobre las esferas públicas afrocolombianas de los años setenta, que permitieron la articulación, circulación y cuestionamiento de las agendas de la negritud descritas hasta el momento. Expresión evidente de lo que se llama diferancia cultural y política negra. Lo primero es que en ellas participaron intelectuales, folcloristas e investigadores con pensamiento de izquierda, de la red de relaciones y colaboraciones creada por Manuel Zapata Olivella y del movimiento de la cultura negra ${ }^{22}$.

Segundo, los seminarios fueron liderados por seminaristas que actuaron como sus líderes; líderes que representaron proyectos ideológicos de la negritud que rivalizan entre sí. Como ilustración, cabe señalar algunas figuras e intelectuales de importancia para el presente estudio. Aquellos que reivindicaron el proyecto de la negritud mestiza, Manuel Zapata Olivella y Carlos Calderón Mosquera; aquellos de pensamiento de izquierda, Dulcey Romero y Orlando Fals Borda; algunos antropólogos de las huellas de africanía, Aquiles Escalante, Nina de Friedemann, Nancy Motta; aquellos cercanos a la negritud liberal, Aureliano Perea Aluma y del proyecto desavasallamiento cultural, Amir Smith Córdoba.

Lo anterior para señalar la pertinencia de los seminarios culturales como esferas públicas afrocolombianas en las que se discutieron, cuestionaron y replantearon agendas políticas y culturales de la negritud. Particularmente, me refiero al IV Semi-

20. Para una lista completa de los aportes conceptuales y analíticos hechos por el movimiento cultural de la cultura negra, para entender la subordinación racial y lo que se puede llamar el desavallasamiento cultural del negro, ver Arboleda (2016); Caicedo (2013); Pisano (2014); Valderrama (2018a).

21. El uso y significado del término grupo étnico o etnia requieren mayor estudio. Sin embargo, lo subrayo porque ya desde los setenta se venía estableciendo la asociación entre comunidades negras y etnia. Es decir, sus usos no han sido exclusivos de los años posteriores a los noventa.

22. Por ejemplo, Manuel Zapata Olivella, Winston Caballero, Nina de Friedemann, Luz Colombia de Gonzales, Blair S Pupo, Edgardo Aguirre Guzmán, Dulcey Romero, Alberto Mendoza Morales, Myriam Días de Pardo, Leo Ortiz, Amir Smith Córdoba, Idalid Ayala, José Consuegra, Jaime Atención Babilonia, Carlos Calderón Mosquera, Emiliano De Armas, N’Dong Undo Ándeme, Nancy Motta, José Manuel Herrera B., Ricardo Rocha, Edgardo Aguirre, Tomas Darío Gutiérrez, Aquiles Escalante, Orlando Fals Borda, Aureliano Perea Aluma y Jacobo Pérez Escobar. 
nario de Cultura Negra, celebrado en Valledupar en 1981. En este, los "participantes (...) cuestionaron los objetivos del Centro para la Investigación de la Cultura Negra, entidad organizadora del seminario. El certamen cobró acalorada discusión cuando Manuel Zapata Olivella entró a defender, en nombre del 'cientificismo abstracto', el mestizaje negro: 'quién puede impedir que yo defienda la parte del blanco que hay en mi'" (El Tiempo, 1981: 6a). El africano N'dong Ondo Andeme se encontraba en el seminario. Él "se pronunciaría para que el público comprendiera cómo puede hacer daño la falta de identidad". Como resultado de la discusión, el seminario decretó la necesidad de orientar estudios demográficos de "la población negra colombiana y presentó la importancia de tener en cuenta quién es realmente negro en una sociedad donde todos quieren ser blancos" (El Tiempo, 1981: 6a).

Así mismo, el intelectual afrocaribeño y miembro del movimiento de cultura negra, Dulcey Romero (1981), dejó claro la necesidad de definir una concepción de la negritud que afirmara la identidad negra. Expresó que:

El concepto de negritud busca el rescate de nuestro pasado cultural en tanto somos hombres negros. Y la cultura como instrumento para generar una conciencia liberadora enmarcada en el contexto general de la lucha de clases (...), o sea que la tarea de rescate de nuestra cultura debe ser la condición indispensable para la adquisición de una conciencia liberadora del avasallamiento de la cultura occidental. (11-12)

Por otro lado, sostuvo, al igual que lo habían hecho otros miembros del movimiento en la revista Negritud años atrás (Uribe, 1977: 29), que:

La negritud debe darle solución dialéctica a la condición de hombres negros y hombres negros explotados, y por ende debe explicarse en un doble accionar dialéctico. Debe rescatar nuestra cultura, identificarnos, hacernos sentir orgullosos de nuestro color, y de nosotros mismos. Pero además debe jugar un papel importante dentro de las masas negras. Y es la toma de conciencia de clase explotada, hacerle comprender que el problema del negro en Colombia y otras partes del mundo se liquidaran en la medida en que cese la explotación del hombre por el hombre, o sea, cuando logremos construir una sociedad más justa, una sociedad sin clases, una sociedad socialista. (Romero, 1981: 11-12)

Lo anterior llevó a plantear cambios radicales en la manera de concebir los procesos organizativos hechos hasta el momento. Como se ha venido describiendo hasta el momento, las esferas públicas afrocolombianas se caracterizaron por ser de tipo cultural y académico. Aquello que hasta el momento el movimiento de la cultura negra se negaba a asumir. Había que pensar en ocupar esferas públicas oficiales. 
La participación del negro en la actividad política es casi nula, pues se manifiesta solo en el sufragio; la causa que motiva al negro a votar no está determinada por la búsqueda de una solución al conjunto de los problemas de su grupo étnico. Así se propuso "soluciones prácticas ya. No podemos seguir simple y llanamente en la práctica conceptual y la investigación teórica. No es conveniente seguir diluyendo en grupos reducidos de intelectuales la temática negra, en donde se ventilan nuestros problemas sin darle solucione que ellos merecen”. (Romero, 1981: 11-12) ${ }^{23}$

Como resultado de estas discusiones sobre el que hacer del movimiento cultural negro, en la celebración del quinto seminario cultural, los asistentes decidieron conformar:

(...) el comité pro unidad nacional para el desarrollo de las comunidadesnegras, integrado por el senador de la República Aureliano Perea Aluma, el sociólogo Amir Smith Córdoba, el antropólogo Winston Cabalero S., el licenciado Dulcey Romero, el pedagogo Arial Lozano Murillo, el administrador de empresas Emiliano de Armas Mitchel; los que, además, quedaron de promover líderes negros. (VISeminario de Cultura Negra, 1983:4)

Los proyectos culturales y políticos descritos en la etapa de la consolidación de los contrapúblicos afrocolombianos demuestran la constitución de esferas públicas que, aunque para los noventa ya habían perdido relevancia social y política, adquirieron un carácter formal y estable. Los escenarios que abrieron para la discusión de proyectos antirracistas reflejaron la diferancia cultural y política negra al reclamar maneras de ser negro/afrocolombiano dentro del marco discursivo de la negritud. Tres proyectos que entrados los años ochenta fueron fuertemente cuestionados por nuevas esferas públicas afrocolombianas: 1) contrapúblicos basados en la ideología cimarrona, 2) la identidad étnica afrocolombiana y 3 ) el feminismo negro y las identidades sexuales diversas. A pesar de la diferancia cultural que cada uno de estos proyectos reivindica, nuevas esferas públicas afrocolombianas se abrieron para discutir, cuestionar y modificar discursos relacionados con las múltiples formas de opresión.

23. Planteamientos como el anterior fueron comunes al inicio de los años ochenta. Organizaciones como la Minga del norte del Cauca, Cimarrón y la Asociación Cultural de Palenque van a plantear similares cuestionamientos sobre la mirada reducida de la negritud, vista simplemente como un problema de raza y racismo, y en la academia. Para estas organizaciones, clase y raza son las claves para explicar la dominación racial de los afrocolombianos en Colombia y el mundo. A su vez, reclamarían mayor trabajo comunitario con las comunidades negras. 


\section{Comentarios finales: estructura política alternativa afrocolombiana}

Se puede destacar varios aprendizajes sobre las luchas sociales y políticas afrocolombianas cartografiadas aquí a través del concepto de contrapúblicos afrocolombianos, y de algunas de sus esferas públicas que surgieron entre los años 1940 y 1980. La posibilidad de identificar estas esferas en la literatura, en el folclor, en la academia, en la cultura y en las organizaciones sociales y políticas nos recuerda que, aun siendo un fenómeno crucial para la construcción de sociedades democráticas, los movimientos sociales no son el único escenario en el que se construyen identidades políticas negras o afrocolombianas. Tampoco son los movimientos sociales los únicos mecanismos para la movilización de agendas políticas e intereses colectivos. A través del escrito, se trató de demostrar que hubo varias construcciones de sentido sobre lo que significó ser negro/afrocolombiano, contrapúblicos afrocolombianos, de acuerdo con las esferas públicas analizadas, y que, en su conjunto, todas ellas describen lo que se ha querido llamar como estructura politica alternativa afrocolombiana: conjunto de esferas públicas afrocolombianas que movilizaron, circularon y presentaron lo que se ha nombrado como la diferancia cultural y política negra en Colombia.

Lo anterior, también, nos sugiere que las movilizaciones sociales y políticas que describen los movimientos sociales se constituyen, más frecuentemente de lo que pensamos, a partir de la diferancia y no, necesariamente, a partir de una identidad colectiva homogénea; son, por el contrario, el resultado de identidades y posiciones políticas en disputa; disputas que no solo reflejan las posiciones del sujeto (clase, raza, género y sexualidad), sino también los deseos frustrados de una supuesta unidad racial, cultural, social y política que no llega a su concreción. Las dificultades de articular estas dos variantes -la diferencia y el deseo de unidad en proyectos políticos comunes- llevan, por lo regular, a rupturas y conflictos entre sectores del movimiento social. Sin embargo, como se demostró en el escrito, hay escenarios en los que discursos contradictorios se encuentran, para repelerse, modificarse, articularse o inventarse nuevos significados y discursos. El valor analítico de estos encuentros y conflictos se debe reconocer por sus continuos aportes en la construcción de contradiscursos políticos e interpretativos de la realidad social del negro en Colombia. Se considera que debemos estudiar estas disputas y observar cómo ellas, además, expresan cuestionamientos ontológicos a aquellos principios y valores heredados de la colonia y la modernidad enseñados a partir de binarismos homogéneos. Es hora de apreciar y abrazar la diferancia cultural y política negra. Es claro que nos han permitido avanzar en la deconstrucción de formas de dominación y opresión que circulan al interior de las comunidades negras. Asumirlo así nos 
ayudaría, inclusive, a cuestionar o matizar aquello que se ha dado en llamar envidia étnica (ver Agudelo, 2005; Wade, 1993).

Finalmente, es perentorio seguir indagando por escenarios de la política negra no considerados en este escrito. La complejidad del campo político afrocolombiano de hoy nos invita a reconocer formas de la política negra desconocidos o no considerados como relevantes. Es decir, debemos desarrollar perspectivas analíticas propias que nos permitan reconocer las particularidades de las luchas sociales y políticas afrocolombianas. Con el concepto de contrapúblicos afrocolombianos se quiso proponer una alternativa a las limitaciones encontradas en las perspectivas de los movimientos sociales. Sin embargo, lo anterior implica, inclusive, identificar y cuestionar los límites del concepto de contrapúblicos afrocolombianos para estudiar la política negra en su totalidad y variabilidad. Es decir, ¿qué tan apropiado sería utilizar el concepto de contrapúblicos afrocolombianos para estudiar fenómenos sociales como las luchas campesinas negras (por ejemplo, los cañeros), los feminismos negros, los grupos estudiantiles, las luchas obreras negras, las organizaciones barriales y populares, y las comunidades LGBTI? Por otro lado, hace falta medir el impacto de los contrapúblicos afrocolombianos en la opinión pública nacional, ya que no hicieron parte del presente escrito (Dawson, 2001). Así, queda claro que hay mucho por hacer y estudiar con respecto a la posibilidad que ofrece estudiar la política negra desde la perspectiva propuesta aquí. Identificar esferas públicas afrocolombianas, análisis de sus contra-discursos y su impacto en la opinión publica promete un área de trabajo académico promisorio por construir, definir y consolidar.

\section{Referencias}

Agudelo, Carlos (2005). Multiculturalismo en Colombia:política, inclusióny exclusión de poblaciones negras (1. ${ }^{\mathrm{a}}$ ed.). Medellín: La Carreta/IRD/Universidad Nacional de Colombia/ICANH.

Álvarez, Sonia; Dagnino, Evelina; Escobar, Arturo (Eds.) (1998). Cultures of Politics/Politics of Cultures: re-Visioning Latin American social Movements. Boulder, CO: Westview Press.

Arboleda, Santiago (2016). Le han florecido nuevas estrellas al cielo. Suficiencias íntimas y clandestinización del pensamiento afrocolombiano. Cali: Poemia.

Archila, Mauricio (2003). Idasy venidas, vueltasy revueltas: protestas sociales en Colombia, 19581990. Bogotá: ICANH/Centro de Investigación y Educación Popular.

Ayala-Diago, César (1988). La evolución del comportamiento político y la cultura negra de Puerto Tejada. En Memorias. II Seminario sobre cultura negra en el Cauca. Popayán: Universidad del Cauca. 
Birenbaum, Michael (2009). The Musical Making of Race and Place in Colombia's Black Pacific. New York: New York University.

Caicedo, José (2013). A mano alzada... memoria escrita de la diáspora intelectual a frocolombiana. Popayán: Sentipensar.

Castillo, Luis Carlos (2007). Etnicidad y nación: el desafio de la diversidad en Colombia (1. ${ }^{\mathrm{a}}$ ed). Cali: Programa Editorial Universidad del Valle.

Collazos, Óscar (2010). Prólogo. Un clásico afroamericano. En Las estrellas son negras (pp. 1328), escrito por Arnoldo Palacios. Bogotá: Ministerio de Cultura.

Comisión Creatividad Social y Política (1988). Creatividad Social y Política. En Primer Congreso de la Cultura Negra de las Américas, Cali, Colombia: actas (1. $\left.{ }^{\mathrm{a}} \mathrm{ed}\right)(\mathrm{pp} .155-157)$, editado por Fundación Colombiana de Investigaciones Folclóricas. Bogotá: Unesco/Fundación Colombiana de Investigaciones Folclóricas/ECOE.

Comisión Etnia Negra y Mestizaje (1988). Etnia Negra y Mestizaje. En Primer Congreso de la Cultura Negra de las Américas, Cali, Colombia: actas (1. ${ }^{\mathrm{a}}$ ed.) (pp 154-158), editado por Fundación Colombiana de Investigaciones Folclóricas. Bogotá: Unesco/Fundación Colombiana de Investigaciones Folclóricas/ECOE.

Comisión Filosofía y Afectividad (1988). Filosofía y Afectividad. En Primer Congreso de la Cultura Negra de las Américas, Cali, Colombia: actas (1. ${ }^{\mathrm{a}}$ ed.) (pp. 151-153), editado por Fundación Colombiana de Investigaciones Folclóricas. Bogotá: Unesco/Fundación Colombiana de Investigaciones Folclóricas/ECOE.

Comisión Material y Artística (1988). Creatividad Material y Artistica. En Primer Congreso de la Cultura Negra de las Américas, Cali, Colombia: actas (1. ${ }^{\mathrm{a}}$ ed.) (pp. 159-163), editado por Fundación Colombiana de Investigaciones Folclóricas. Bogotá: Unesco/Fundación Colombiana de Investigaciones Folclóricas/ECOE.

Dawson, Michael (2001). Black Visions: the Roots of Contemporary African-American Political Ideologies. Chicago, IL: University of Chicago Press.

Depestre, René (1984). Hello and goodbye to negritud. En Africa in Latin America: Essays on History, Culture, and Socialization (pp. 281-272), editado por Manuel Moreno Fraginals. New York, NY: Holmes \& Meier.

Díaz, Natanael (9 de agosto de 1947). Diego Luis Córdoba: un negro visto por otro negro. Sábado, pp. 2-11.

Eley, Geoff (1992). Nations, Publics, and Political Cultures: Placing Habermas in the Nineteenth Century. En Habermas and the Public Sphere (pp. 289-357), editado por Craig Calhoun. Cambridge, MA: MIT Press.

Éxito en el seminario de cultura negra. (20 de octubre de 1981). El Tiempo, pp. 6a. 
Fligstein, Neil; McAdam, Doug (2012). A Theory of Fields. New York, NY: Oxford University Press.

Flórez, Juliana (2010). Lecturas emergentes: decolonialidad y subjetividad en las teorías de movimientos sociales ( $1 .^{\mathrm{a}}$ ed.). Bogotá: Pontificia Universidad Javeriana.

Fraser, Nancy (1990). Rethinking the Public Sphere: A Contribution to the Critique of Actually Existing Democracy. Social Text, 25/26, 56-8o. https://doi.org/10.2307/466240

Gregory, Steven (1998). Black Corona: Race and the Politics of Place in an Urban Community. Princeton, NJ: Princeton University Press.

Habermas, Jürgen (1999). The Structural Transformation of the Public Sphere: An Inquiry into a Category of Bourgeois Society. Cambridge, MA: MIT Press.

Hall, Stuart (1998). Cultural Identity and Diaspora. En Identity: Community, Culture, Difference (pp. 222-237), editado por Jonathan Rutherford. London: Lawrence \& Wishart.

Hanchard, Michael (2006). Party/Politics: Horizons in Black Political Thought. Oxford, NY: Oxford University Press.

Hurtado, Teodora (2001). La protesta social en el norte del Cauca y el surgimiento de la movilización étnica afrocolombiana. En Acción colectiva, estado y etnicidad en el Pacífico colombiano (1. ${ }^{a}$ ed.) (pp. 95-122), editado por Mauricio Pardo. Bogotá: ICANH/Colciencias.

Karabalí, Manuel (1947). Estudio del negro en Colombia. Cromos, 64(1597), p. 9.

Lao-Montes, Agustín (2010). Cartografías del campo político afrodescendiente en América Latina. En Debates sobre ciudadanía y políticas raciales en las Américas Negras (pp. 281-328), editado por Claudia Rosero-Labbe; Agustín Lao-Montes; César Rodríguez. Bogotá: Universidad Nacional de Colombia.

Lleras Restrepo, Carlos (1961a). La magia de la cumbia. Seminario Política y algo más, pp. 8-9.

Lleras Restrepo, Carlos (1961b). La vida de los estudiosos. Seminario Política y algo más, pp. 8-9.

Lleras Restrepo, Carlos (1961c). Un líder de color. Seminario Política y algo más, pp. 8-9.

Martán Góngora, Helcías (12 de abril de 1959). Canto negro para Delia Zapata. El Tiempo, pp. 2.

McAdam, Doug (1999). Political process and the development of Black insurgency, 1930-1970 (2. ${ }^{\mathrm{a}}$ ed.). Chicago, IL: University of Chicago Press.

Melucci, Antonio (1996). Challenging Codes: Collective Action in the Information Age. Cambridge, NY: Cambridge University Press.

Mina, Mateo (1975). Esclavitud y libertad en el valle del río Cauca. Bogotá: Fundación Rosca de Investigación y Acción Social. 
Mosquera, José (2002). Los grandes retos que debe resolver el pueblo afrocolombiano. Medellín: Licher.

Múnera, Leopoldo (1998). Rupturas y continuidades: poder y movimiento popular en Colombia, 1968-1988. Bogotá: Universidad Nacional de Colombia.

Paschel, Tiana (2016). Becoming Black Political Subjects: Movements and Ethno-racial Rights in Colombia and Brazil. Princeton, NJ: Princeton University Press.

Pisano, Prieto (2012). Liderazgo político «negro» en Colombia, 1943-1964. Bogotá: Universidad Nacional de Colombia.

Pisano, Prieto (2014). Movilidad social e identidad «negra» en la segunda mitad del siglo XX. ACHSC, 41(1), 179-199.

Prescott, Laurence (2000). Without Hatreds or Fears: Jorge Artel and the Struggle for Black Literary Expression in Colombia. Detroit, MI: Wayne State University Press.

Romero, Dulcey (octubre-noviembre de 1981). Ponencia del Atlántico. Presencia Negra, 18, 11-12.

Roux, Gustavo (1991). Orígenes y expresiones de una ideología liberal. Boletín Socioeconómico, $22,3-26$.

Sanders, James (2004). Contentious Republicans: Popular Politics, Race, and Class in Nineteenth-century Colombia. Durham: Duke University Press.

Sigue la discriminación racial. (23 de junio de 1977). El Pueblo.

Singh, Nikhil (2005). Black is a Country: Race and the Unfinished Struggle for Democracy. Cambridge, MA: Harvard University Press. Recuperado de http://hdl.handle.net/2027/heb.31493

Smith-Córdoba, Amir (1977). Movimiento. Negritud, 1, 25-26.

Thayer, Millie (2010). Making Transnational Feminism: Rural Women, NGO Activists, and Northern Donors in Brazil. New York, NY: Routledge.

Tirado, Álvaro (2014). Los años sesenta: una revolución en la cultura (1. ${ }^{\mathrm{a}}$ ed.). Bogotá: Debate.

Valderrama, Carlos (2013). Folclore, raza y racismo en la política cultural e intelectual de Delia Zapata Olivella. El campo político-intelectual afrocolombiano. Revista CS, 12, 259-296. https://doi.org/10.18046/recs.i12.1674

Valderrama, Carlos (2018a). The Negritude Movements in Colombia (Tesis de doctorado). Universidad de Massachusetts, Amherst, Massachusetts, Estados Unidos.

Valderrama, Carlos (2018b). El arte literario y la construcción oral del territorio. Pensamiento crítico afrocolombiano. Revista Colombiana de Antropología, 54(2), 93-117. https://doi. org/10.22380/2539472X.463 
Velásquez, Rogelio (20 de agosto de 1949). Palabras de un libro. Las estrellas son negras. Sábado, s.p.

VI Seminario de Cultura Negra. (Febrero-marzo de 1983). Presencia Negra, 33: 4.

Wabgou, Maguemati; Arocha-Rodríguez, Jaime; Salgado-Cassiani, Aiden; Carabalí-Ospina, Juan (2012). Movimiento social afrocolombiano, negro, raizal y palenquero: el largo camino hacia la construcción de espacios comunesy alianzas estratégicas para la incidencia política en Colombia. Bogotá: Universidad Nacional de Colombia/Instituto Unidad de Investigaciones Jurídico-Sociales Gerardo Molina.

Wade, Peter (1993). Blackness and Race Mixture: The Dynamics of Racial Identity in Colombia. Baltimore, MD: Johns Hopkins University Press.

Wade, Peter (1995). The Cultural Politics of Blackness in Colombia. American Ethnologist, 22(2), 341.

Warner, Michael (2010). Publics and Counterpublics (1. ${ }^{\mathrm{a}}$ ed.). New York, NY: Zone Books.

Zapata Olivella, Manuel (1990). iLevántate mulato! Por mi raza hablará el espíritu (1. ${ }^{\mathrm{a}}$ ed.). Bogotá: Rei Andes. 